\title{
Thermal rearrangement of tert-butylsulfinamide
}

\author{
Veera Reddy Arava*1, Laxminarasimhulu Gorentla ${ }^{1}$ \\ and Pramod Kumar Dubey ${ }^{2}$
}

\section{Letter}

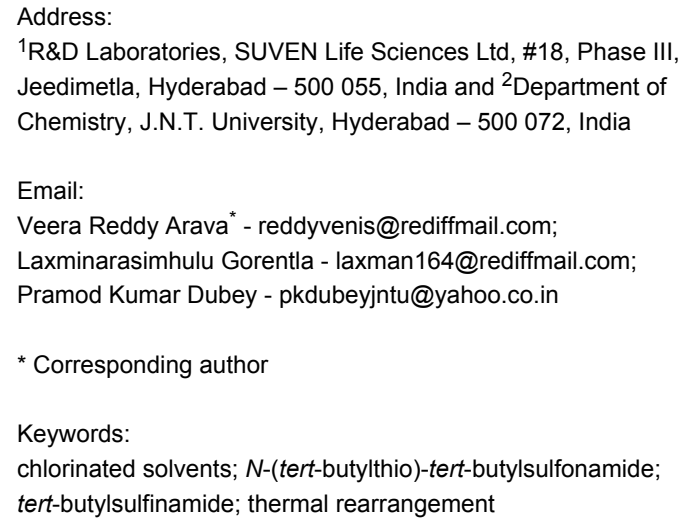

\begin{abstract} more stable $N$-(tert-butylthio)-tert-butylsulfonamide.

\section{Introduction}

Over the past decade, an ever increasing number of methods based upon the chiral amine reagent tert-butylsulfinamide (1) (Figure 1) has become one of the most extensively used synthetic approaches for both the production and discovery of drug candidates [1]. In particular, the tert-butylsulfinyl group showed high levels of asymmetric induction in many processes. The importance of these reagents ( $R$ and $S$ ) is evident by the number of manufacturers $(>75)$ and by the number of publications $(>400)$.
\end{abstract}

tert-Butylsulfinamides are unstable above room temperature, and in chlorinated solvents they undergo rearrangement to form the

\section{Results and Discussion}

During our studies [2] on the industrial utilization of these two reagents $(R$ and $S$ ), we found an interesting observation, i.e.,

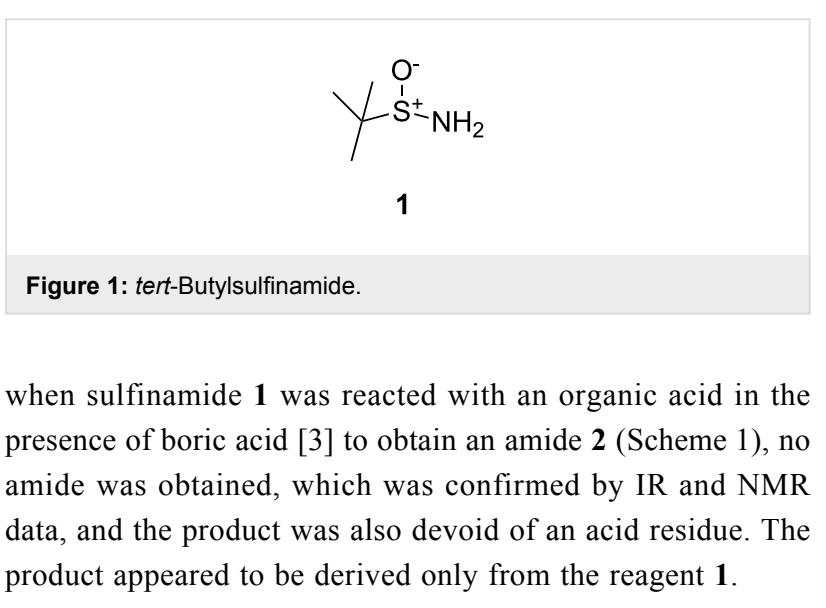




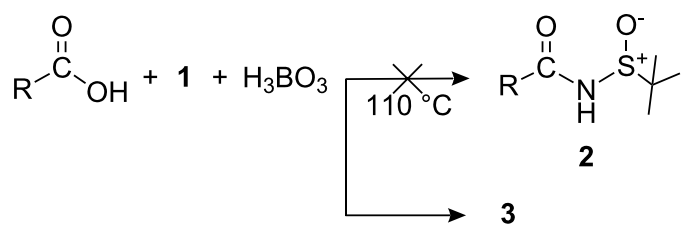

Scheme 1: Synthesis of acid amide.

From the spectral data, structure 3 was assigned to the product shown in Figure 2. The structure of $\mathbf{3}$ was confirmed by chemical synthesis (Scheme 2) and finally by XRD [4] (Figure 3). Both tert-butylsulfanyl chloride 4 (Scheme 3 ) and tert-butylsulfonamide 5 (Scheme 4) were prepared by known procedures $[5,6]$.

A possible mechanism for the proposed rearrangement is shown in Scheme 5.

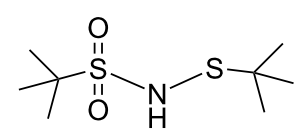

3

Figure 2: $\mathrm{N}$-(tert-butylthio)-tert-butylsulfonamide.

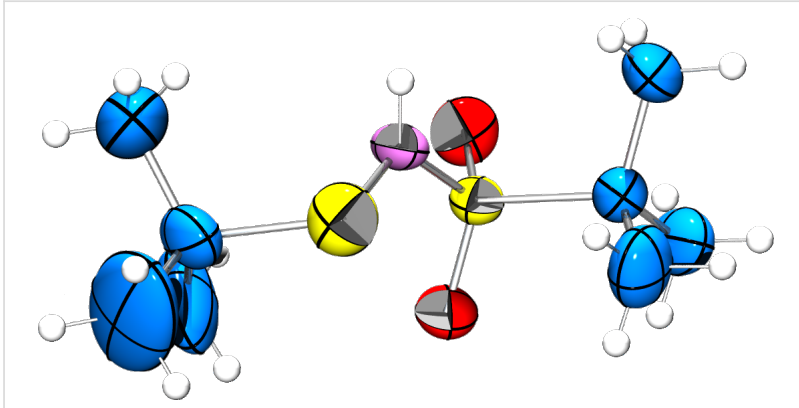

Figure 3: ORTEP diagram of 3.

$$
\begin{aligned}
& \chi_{\mathrm{SH}}+\mathrm{Cl}_{2} \underset{\mathrm{RT}}{\stackrel{n \text {-pentane }}{\longrightarrow}} \chi^{\mathrm{S}}-\mathrm{Cl}+y_{\mathrm{S}-\mathrm{S}} \\
& \text { tert-butylthiol } \quad-\mathrm{HCl} \quad 4
\end{aligned}
$$

Scheme 3: Synthesis of tert-butylsulfanyl chloride.

$$
\chi^{\stackrel{\mathrm{O}}{\mathrm{S}}-\mathrm{Cl}}+\mathrm{NaN}_{3} \stackrel{\mathrm{ACN} / \mathrm{H}_{2} \mathrm{O}}{\underset{70-75^{\circ} \mathrm{C}}{\longrightarrow}} \underbrace{\mathrm{S}}_{\mathrm{O}}-\stackrel{\mathrm{O}}{\mathrm{O}}-\mathrm{NH}_{2}
$$

tert-butylsulfinyl chloride

5

Scheme 4: Synthesis of tert-butylsulfonamide.

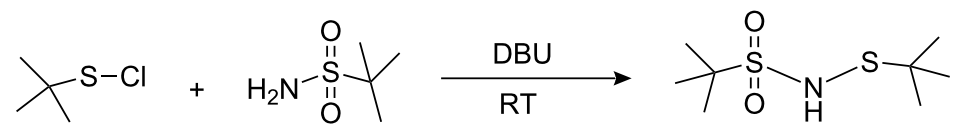

4 5
3

Scheme 2: Chemical synthesis of 3.

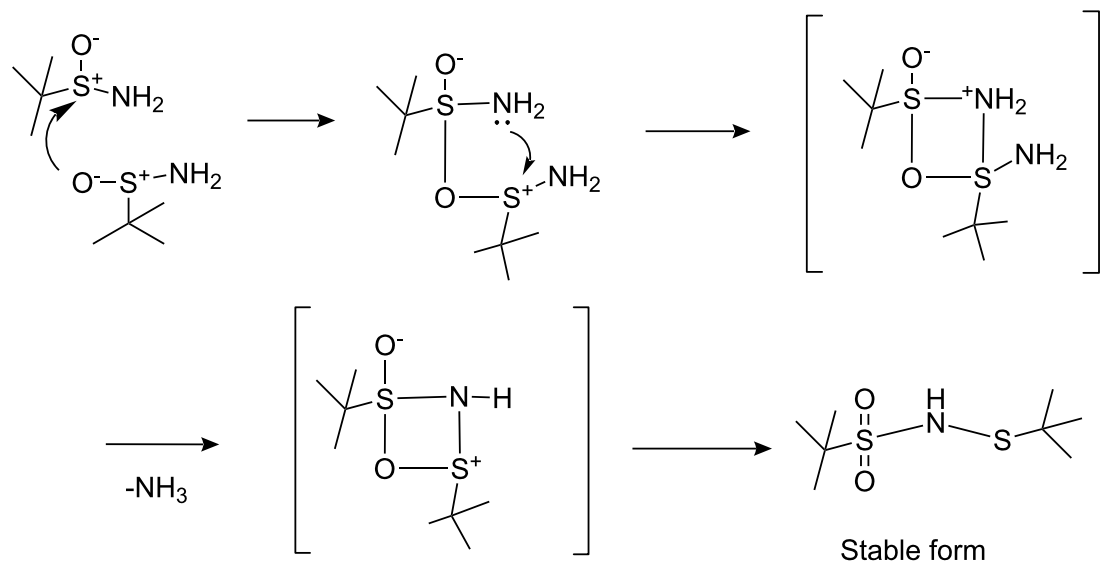

Scheme 5: Proposed mechanism for rearrangement. 


\begin{tabular}{|c|c|c|c|c|c|c|}
\hline \multirow[t]{2}{*}{ Entry } & \multicolumn{5}{|c|}{ Reaction conditions } & \multirow[t]{2}{*}{ Yield $(\%)^{2}$} \\
\hline & $\begin{array}{l}\text { Starting } \\
\text { material }\end{array}$ & $\begin{array}{c}\text { Reagent / condition } \\
\text { type }\end{array}$ & Solvent & $T\left({ }^{\circ} \mathrm{C}\right)$ & Time $(\mathrm{h})$ & \\
\hline 1 & $(R)$-isomer & - & - & 110 & 3 & 27 \\
\hline 2 & $(R)$-isomer & - & toluene & 110 & 48 & 70 \\
\hline 3 & $(R)$-isomer & - & o-xylene & 140 & 48 & 64 \\
\hline 4 & $(R)$-isomer & - & ethylene dichloride & 80 & 72 & $40+20^{c}$ \\
\hline 5 & $(R)$-isomer & - & $\mathrm{CHCl}_{3}$ & 65 & 72 & 25 \\
\hline 6 & $(R)$-isomer & - & toluene & 110 & 48 & 70 \\
\hline 7 & $(R)$-isomer & boric acid ( 1.0 equiv) & toluene $\left(\mathrm{u} / \mathrm{N}_{2}\right)$ & 110 & 24 & 65 \\
\hline 8 & $(R)$-isomer & boric acid (1.0 equiv) & toluene & 110 & 24 & 65 \\
\hline 9 & $(R)$-isomer & boric acid ( 0.5 equiv) & toluene & 110 & 48 & 60 \\
\hline 10 & $(R)$-isomer & $\mathrm{MeSO}_{3} \mathrm{H}$ & toluene & 110 & 1 & 27 \\
\hline 11 & $(R)$-isomer & tartaric acid & toluene & 110 & 24 & 38 \\
\hline 12 & $(R)$-isomer & citric acid & toluene & 110 & 24 & 16 \\
\hline 13 & $(R)$-isomer & $p$-TSA & toluene & 110 & 24 & 38 \\
\hline 14 & $(R)$-isomer & sonication & $\mathrm{CHCl}_{3}$ & $\mathrm{RT}$ & 2 & $34^{b}$ \\
\hline 15 & $(R)$-isomer & sonication & DMF & RT & 1 & $2^{b}$ \\
\hline 16 & $(R)$-isomer & sonication & ethyl acetate & $\mathrm{RT}$ & 1 & $5^{\mathrm{b}}$ \\
\hline 17 & $(R)$-isomer & sonication + boric acid & $\mathrm{CHCl}_{3}$ & $\mathrm{RT}$ & 1 & $16^{b}$ \\
\hline 18 & $(R)$-isomer & sonication $+p$-TSA & $\mathrm{CHCl}_{3}$ & RT & 0.5 & $23^{b}$ \\
\hline 19 & $(R)$-isomer & - & toluene & $\mathrm{RT}$ & 144 & 3 \\
\hline 20 & $(R)$-isomer & - & $\mathrm{CHCl}_{3}$ & $\mathrm{RT}$ & 144 & $21^{b}$ \\
\hline 21 & $(R)$-isomer & - & $\mathrm{MeOH}$ & $\mathrm{RT}$ & 144 & $3^{b}$ \\
\hline 22 & $(R)$-isomer & benzoyl peroxide & toluene & 110 & 48 & 60 \\
\hline 23 & $(R)$-isomer & TEMPO & toluene & RT - 110 & 40 & $9^{b}$ \\
\hline 24 & $(R)$-isomer & 2,6-di-tert-butylphenol & toluene & 110 & 24 & 75 \\
\hline 25 & $(S)$-isomer & - & toluene & 110 & 48 & 70 \\
\hline 26 & $(R)$-isomer & MW 150 Watt & DMF & 150 & 0.5 & 70 \\
\hline
\end{tabular}

alsolated yield, ${ }^{b} \%$ conversion in HPLC, ${ }^{c}$ recovered starting material with SOR $+5^{\circ}$

First it is assumed that the product is formed only by the degradation of reagent $\mathbf{1}$. Further experiments, in the presence of acids (entries 7 to 13, Table 1) or the absence of acids (entries 1 to 6 , Table 1), under sonication (entries 14 to 18 ) and with microwave irradiation (entry 26), confirmed the assumption that the reagent is thermally unstable. Also the rearrangement is likely not to proceed by a homolytic fission (radical) mechanism, because the rate of reaction is not affected either by benzoyl peroxide, by TEMPO a radical initiator (entries 22 and 23 ) or by a radical inhibitor 2,6-di-tert-butylphenol (entry 24).

When the reagent $\mathbf{1}$ alone was subjected to thermal rearrangement (entry 1), complete consumption of starting material was observed. Only $27 \%$ product was isolated and $73 \%$ of the material was lost by vaporitation. When the reaction was carried out in the presence of solvents such as toluene (entries 2, 6 and 24), $o$-xylene (entry 3 ), or solvents with reagents such as boric acid (entries 7, 8 and 9), methanesulphonic acid (entry 10), $p$-TSA (entry 13), benzoyl peroxide (entry 22), 2,6-di-tert- butylphenol (entry 23) or with microwave irradiation (entry 25), complete consumption of starting material was observed. In other cases (entries 4, 5, 11 and 12), 10 to $30 \%$ of the starting material was recovered without racemization.

\section{Conclusion}

We found that both ( $R$ and $S$ ) tert-butanesulfinamides are unstable above room temperature and in chlorinated solvents.

\section{Experimental}

See Supporting Information File 1 for full experimental data.

\section{Supporting Information}

\section{Supporting Information File 1}

Full experimental data.

[http://www.beilstein-journals.org/bjoc/content/ supplementary/1860-5397-7-2-S1.pdf] 


\section{Acknowledgements}

We wish to thank Prof. A. Srikrishna of IISc. (Bangalore) for the X-ray analysis and the management of Suven for providing excellent facilities.

\section{References}

1. Robak, M. T.; Herbage, M. A.; Ellman, J. A. Chem. Rev. 2010, 110, 3600-3740. doi:10.1021/cr900382t

2. Reddy, A. V.; Rao, S. U. B.; Narasimha, G. L.; Dubey, P. K.

Synth. Commun. 2009, 39, 1451-1456.

doi:10.1080/00397910802519216

3. Mylavarapu, R. K.; Kondaiah, G. C. M.; Kolla, N.; Veeramalla, R.; Koilkonda, P.; Bhattacharya, A.; Bandichhor, R. Org. Process Res. Dev. 2007, 11, 1065-1068. doi:10.1021/op700098w

4. Deposited as CCDC 773082 (2010).

5. Himel, C. M.; Park, M. Production of tertiary alkyl thio sulfenyl chlorides. U.S. Patent 2,934,563, April 26, 1960.

6. Sharpless, K. B.; Gontcharov, A. V.; Liu, H. Aminohydroxylation of olefins with tert-alkyl sulfonamides. U.S. Patent 6,008,376, Aug 21, 1999.

\section{License and Terms}

This is an Open Access article under the terms of the Creative Commons Attribution License (http://creativecommons.org/licenses/by/2.0), which permits unrestricted use, distribution, and reproduction in any medium, provided the original work is properly cited.

The license is subject to the Beilstein Journal of Organic Chemistry terms and conditions:

(http://www.beilstein-journals.org/bjoc)

The definitive version of this article is the electronic one which can be found at: $\underline{\text { doi: } 10.3762 / \text { bjoc. } 7.2}$ 